\title{
Yaqob: Impacts Of Re-Heating And Compaction Temperatures On Hot Mix Asphalt
}

\section{Impacts Of Re-Heating And Compaction Temperatures On Hot Mix Asphalt Volumetrics}

\section{Romel Nano Yaqob}

\section{Assistant lecturer/ University of Kirkuk/Civil Engineering Department}

\begin{abstract}
The need for accurate, consistent laboratory tests of the volumetric properties of the hot mix asphalt (HMA) has become increasingly important in the past few years. The objective of this study was to evaluate the effect of re-heating and compaction temperatures on the volumetric properties of the HMA mixtures. These effects were studied with two experiments. In the first experiment, mix was compacted after 0,3 and 20 hour's storage time. In the second experiment, mix was compacted at three different temperatures; standard target compaction temperature for the grade of asphalt cement in the mixture, target $-14^{\circ} \mathrm{C}$ and target $+14^{\circ} \mathrm{C}$. Above and under superpave restricted zone graded mixtures comprised of two sources of aggregates, and one type of binder were compacted with the Marshall compactor machine and their volumetric properties measured. The results show that there are significant differences in volumetric properties as the mix stored by 3 hours or more and changes in volumetric properties occur as the compaction temperature varies.
\end{abstract}

Keywords: Volumetrics, compaction temperature, storage time, re-heating

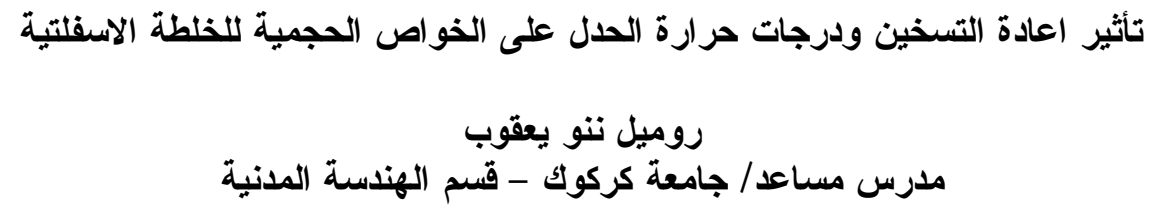

الخلاصة

ان الحاجة الى الفحوصات المختبرية الثابتة والدقيقة للحصول على الخواص الحجمبة للخلطة الاسفلتية الحارة (HMA)

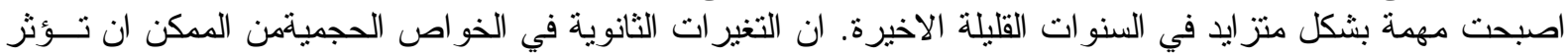

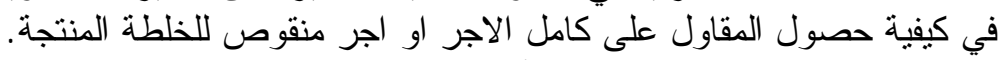

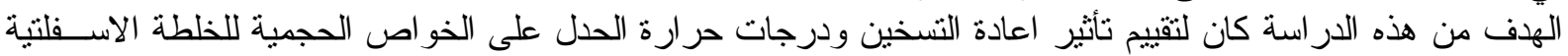

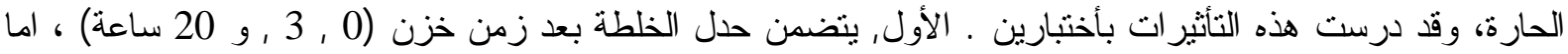

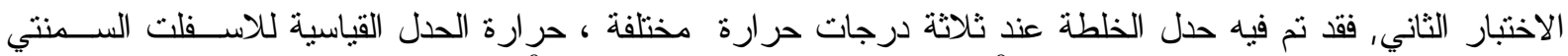

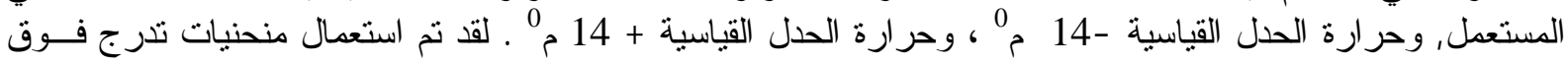

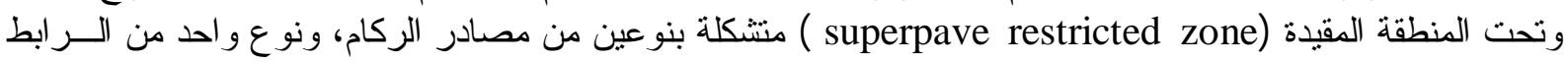
الاسفلتي لتشكل خلطة لتحدل بجهاز مارشال ثم قياس الخو اص الت الحجمية.

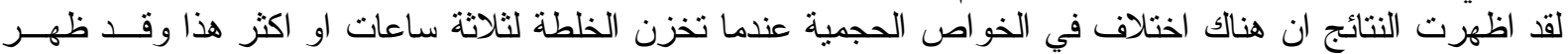
اختلاف في الخواص الحجمية ايضا عند تغيير درجات حرارة الحندل.

الكلمات الالة: حجمّي ,درجات حر ارة الحدل, زمن الخزن، اعادة التسخين 


\section{Introduction}

In the hot mix asphalt (HMA) construction industry, the need for accurate, consistent volumetric measurements has recently become more important. Since more states are relying on volumetric properties to both design the mixture and then to evaluate the final product during the construction phase, the need for reliable test results has become a necessity.

It is believed by some that discrepancies between agency and contractor test results may be partially related to re-heating mixture samples that have cooled below compaction temperatures. Also, when re-heating mixtures, the compaction temperature, if not closely monitored, could be inaccurate and thus cause more deviation. The effects of these two issues need to be looked at more closely to determine if they significantly affect sample volumetrics. [1].

\section{Hot Mix Asphalt Volumetrics}

There are three volumetric properties most commonly measured to evaluate the physical characteristics of HMA [2]: voids in total mix (VTM), voids in mineral aggregate (VMA), and voids filled with asphalt cement (VFA). These mixture properties are explained in figure 1 and defined as follows:

Voids in Total Mix (VTM): the total of the small pockets of air between the coated aggregate particles throughout a compacted paving mixture, expressed as a percent of the volume of the compacted paving mixture.

Voids in mineral aggregate (VMA): the volume of intergranular void space between the aggregate particles of a compacted paving mixture that includes the air voids and asphalt cement not absorbed in to the aggregate.

Voids filled with asphalt cement (VFA): the volume of the VMA, expressed as a percentage, which is filled with the asphalt cement.

These properties are measured during mix design and production of HMA.
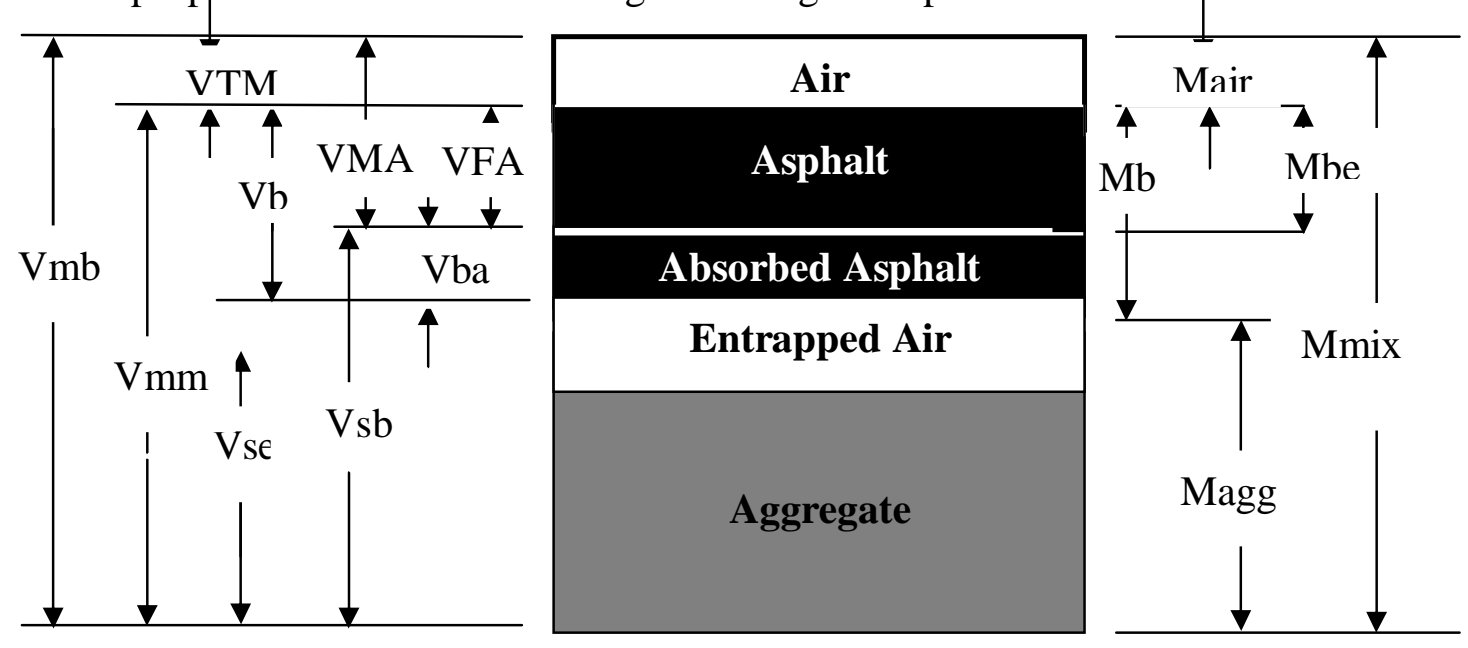

$\mathrm{VMA}=$ Volume of voids in mineral aggregate

$\mathrm{Vmb}=$ Bulk volume of compacted mix

$\mathrm{Vmm}=$ Voidless volume of paving mix

$\mathrm{VFA}=$ Volume of voids filled with asphalt

$\mathrm{VTM}=$ Volume of air voids

$\mathrm{Vsb}=$ Volume of mineral aggregate

(By effective specific gravity)

(By bulk specific gravity)
Mmix = Total mass of asphalt mixture

$\mathrm{Mb}=$ Mass of asphalt binder

Mbe $=$ Mass of effective aggregate binder

Magg $=$ Mass of aggregate

Mair $=$ Mass of air $=0$

Vse $=$ Volume of mineral aggregate

$\mathrm{Vb}=$ Volume of asphalt binder

$\mathrm{Vba}=$ Volume of absorbed asphalt binder

Figure 1: Components of a Compacted HMA Specimen [2] 


\section{Yaqob: Impacts Of Re-Heating And Compaction Temperatures On Hot Mix Asphalt}

\section{Background}

The different ways that the mixtures are handled prior to testing is believed to play a role in the variability between governmental agency and contractor measured properties. One common reason given for these differences has been the effect of re-heating the HMA mixture prior to laboratory compaction. There are two reasons for re-heating of the mixture. one reason for re-heating the mixture is a result of transporting the sample to the laboratory for testing, while the second occurs when either referee or verification samples must be tested. These samples will have cooled for hours or even days. In order to compact these mixtures they must be re-heated to compaction temperatures. When mixtures are re-heated for compaction, another issue develops that may affect the final properties of compacted samples. This issue is control of test temperature, that the temperature at which the mixture is compacted might be either higher or lower than the target compaction temperature if no standard procedure is followed for re-heating nor for selecting compaction temperature. [1]

\section{Temperature and Compactibility}

Because asphalt cement viscosity changes with temperature, mix compaction temperature is important. [3] However, one study performed at the University of Wisconsin Madison, NCHRP 9-10 [4], showed surprising data that indicated little change in density with change in compaction temperature. This data showed that although the asphalt cement viscosity changed by 3 - orders of magnitude between $80^{\circ} \mathrm{C}$ and $155^{\circ} \mathrm{C}$, compaction temperature had little to no effect on volumetric properties of the compacted samples. A second evaluation was carried out using other modes of laboratory compaction along with the superpave gyratory compactor (SGC). In this evaluation similar mixtures samples were compacted on three different compactors (Marshall, Hveem, and SGC) utilizing three different compaction temperatures $\left(160,115\right.$ and $\left.80^{\circ} \mathrm{C}\right)$. The results of this work, as illustrated in figure 2 , showed that all three compactors differed in terms of sensitivity to temperature, with the SGC being the least sensitive. [5]

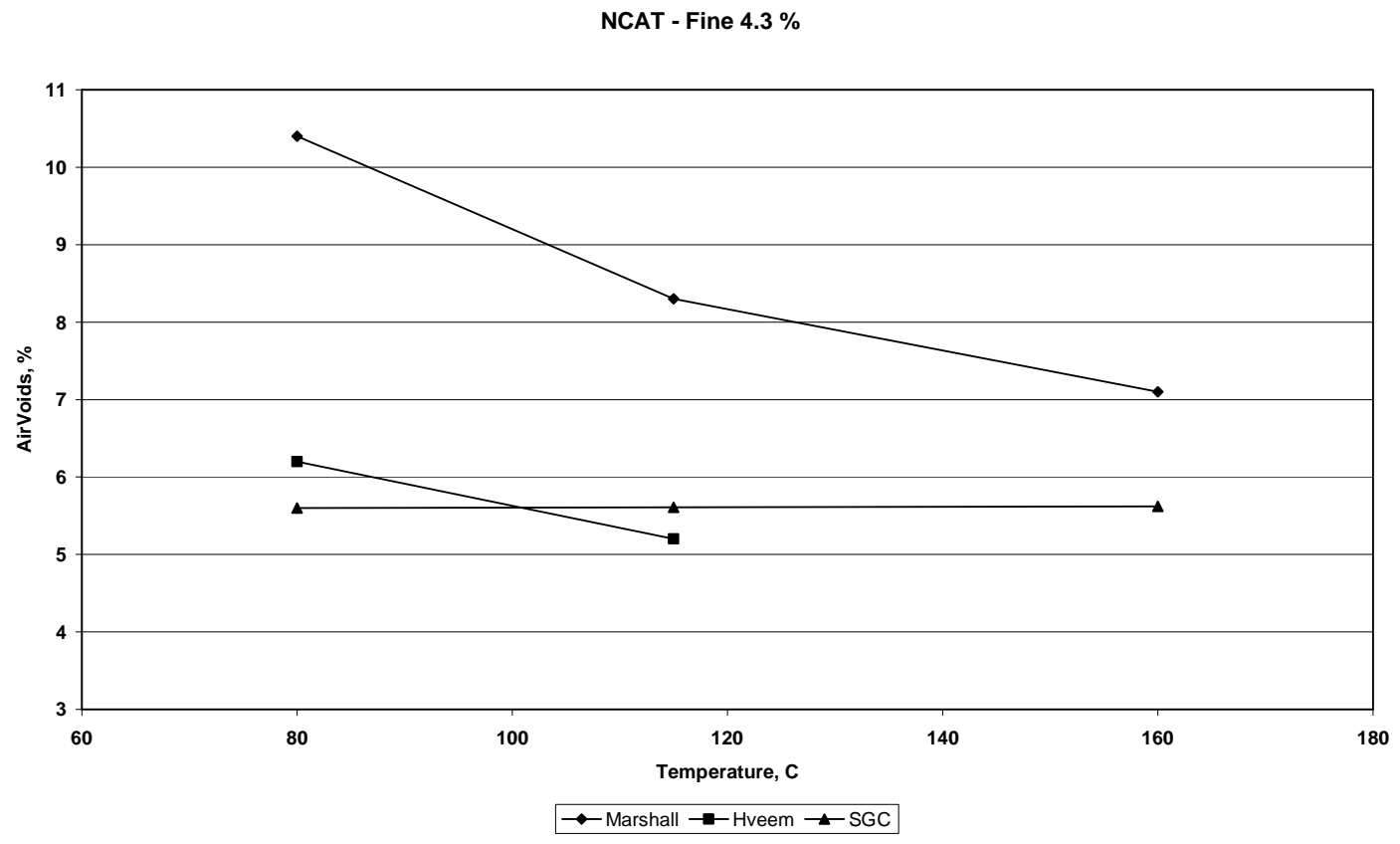

Figure 2: Effect of Temperature on Air Voids measured after Compaction Using Different Compaction Methods for HMA containing a Fine Crushed

Gravel Mixture. [5] 
The objective of this study was to evaluate the effects of both re-heating and compaction temperature on volumetric properties of HMA mixtures. To accomplish this, various mixtures were compacted at three temperatures with the same compactive effort to determine their volumetric properties. In order to consider a range of mixtures, two gradations of above and below superpave restricted zone as shown in table 1were used, two source of aggregate from Al-Nebaey and Daquq Soo which differs in their properties as shown in table 2 were used, and one grade (40-50) penetration graded of asphalt cement were utilized from daurah refinery, and its properties were shown in table 3.

Three storage times ( 0,3 and 20 hours) were used at the target temperature throughout the study. Storage time refers to the additional time a mixture was allowed to sit at room temperature (approximately $25^{\circ} \mathrm{C}$ ) after the mixing is finished. The zero (0) storage time means that no cooling time was allowed between sampling and heating to compaction temperature. The three hour samples represent samples that are transported to another laboratory testing. The twenty hour samples might represent verification samples that may tested after several days of storage.

In addition, the effect of compaction temperature was studied by compacting identical samples at three different compaction temperatures at (0) storage time. The temperatures used in this phase of the study were the standard compaction temperature for the specific asphalt grade being tested and the standard compaction temperature $\pm 14^{\circ} \mathrm{C}$. These temperatures were 135,149 and $163^{\circ} \mathrm{C}$ to stimulate compaction temperatures that are too high and too low. All mixtures were compacted with the Marshall compactor with the consistent compactive effort of 50 blows/each face.

Table 1: Percent Passing (by weight of total aggregate) of Selected Dense Gradations for $19.0 \mathrm{~mm}$ Nominal Maximum Size.[6]

\begin{tabular}{|c|c|c|c|c|c|c|c|c|c|c|c|}
\hline u $\stackrel{0}{9}$ & $\stackrel{0}{\dot{u}}$ & i & $\dot{8}$ & 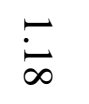 & $\stackrel{N}{\omega}$ & $\stackrel{+}{\dot{v}}$ & $\begin{array}{l}0 \\
\text { ir }\end{array}$ & $\vec{N}$ & $\overrightarrow{0}$ & $\begin{array}{l}N \\
\stackrel{N}{0}\end{array}$ & SieveOpening $(\mathrm{mm})$ \\
\hline 5 & 7 & 20 & 28 & 34 & 40 & 50 & 75 & 85 & 95 & 100 & $\%$ passing ARZ \\
\hline 5 & 7 & 8.5 & 11 & 16.5 & 27 & 50 & 75 & 85 & 95 & 100 & $\%$ passing $\mathrm{BRZ}$ \\
\hline
\end{tabular}

Table 2: The Properties of Coarse Aggregate from the Two Different Sources. [7]

\begin{tabular}{|c|c|c|c|c|}
\hline properties & ASTM & SORB & Nibaey & $\begin{array}{l}\text { Daquq } \\
\text { Soo }\end{array}$ \\
\hline Bulk Specific Gravity & C 127 & & 2.57 & 2.617 \\
\hline Effective Specific Gravity & \multirow[b]{2}{*}{ D 2041} & & 2.576 & 2.631 \\
\hline \% Asphalt Absorption & & & 0.093 & 0.195 \\
\hline$\%$ Gypsum & & $<=1 \%$ & 3.00 & 0.2 \\
\hline$\%$ Soundness & C 88 & $<=12$ & 2.26 & 1.76 \\
\hline $\begin{array}{l}\text { \% Coated Area with Asphalt } \\
\text { After Immersion in Water }\end{array}$ & D 1664 & $>95$ & 91 & 95 \\
\hline \% Wear ( L.A. Abrasion) & C 131 & $<=35$ & 26.1 & 20.4 \\
\hline $\begin{array}{l}\text { \% Clay Lump \& Friable } \\
\text { Particles }\end{array}$ & C 142 & $<=3$ & 1.35 & 0.76 \\
\hline \multicolumn{5}{|c|}{$\%$ Mineral Compound } \\
\hline$\%$ Calcite & & & 12.7 & 33.6 \\
\hline$\%$ Quartz & & & 87.3 & 66.4 \\
\hline
\end{tabular}


Table 3: Physical properties of asphalt cement [7]

\begin{tabular}{|c|c|c|c|}
\hline Test & Unit & ASTM & $\begin{array}{c}\text { Results } \\
\text { D(40-50) }\end{array}$ \\
\hline Penetration $25^{0} \mathrm{C}, 100 \mathrm{gm}, 5 \mathrm{sec}$. & $1 / 10 \mathrm{~mm}$ & D 5 & 42 \\
\hline Absolute Viscosity at $60^{\circ} \mathrm{C}$ & Poise & D 2171 & 3068 \\
\hline Kinematic Viscosity at $135{ }^{0} \mathrm{C}$ & C St. & D 2170 & 373 \\
\hline Ductility $\left(25^{0} \mathrm{C}, 5 \mathrm{~cm} / \mathrm{min}.\right)$ & $\mathrm{Cm}$ & D 113 & $>100$ \\
\hline Softening point (Ring \& Ball) & $\mathrm{C}^{0}$ & D 36 & 51.0 \\
\hline Specific gravity at $25^{0} \mathrm{C}$ & & D 70 & 1.04 \\
\hline Flash point ( Cleveland Open Cup) & $\mathrm{C}^{0}$ & D 92 & 332 \\
\hline \multicolumn{4}{|c|}{ After Thin- Film Oven Test } \\
\hline Penetration of Residue & $1 / 10 \mathrm{~mm}$ & D 5 & 39 \\
\hline Ductility of Residue & $\mathrm{Cm}$ & D 113 & 82 \\
\hline Loss on Heat at $135^{\circ} \mathrm{C}, 50 \mathrm{gm}, 5 \mathrm{hrs}$ & $\%$ & D 1754 & 0.82 \\
\hline
\end{tabular}

\section{Data presentation}

In order to delineate the different mixtures used in this paper a coding system was developed, which is used for the graphical presentations throughout this paper, and shown as follows:

ARZ= Above Restricted Zone Gradation

BRZ= Below Restricted Zone Gradation

$\mathrm{DA}=$ Daquq Soo source of aggregate

NA= Nebaey Source of Aggregate, and

$\mathrm{SORB}=$ Iraqi Standard Specification for Roads and Bridges

\section{Results and Discussion}

The conventional Marshall Method test was conducted to find the optimum asphalt content for the ARZ-DA and BRZ-DA mixture type. Other types of mixture already have the optimum asphalt content [6]. The optimum asphalt content with regard to mixture type is shown in table 4.

Table 4: The optimum asphalt content with regard to mixture type

\begin{tabular}{|c|c|c|c|c|}
\hline Mixture type & ARZ-DA & ARZ-NA & BRZ-DA & BRZ-NA \\
\hline \%Optimum Asphalt Content & 5.0 & 5.1 & 4.5 & 4.7 \\
\hline
\end{tabular}

In the re-heating phase of the study, samples of each of the four mixture combination were compacted with the Marshall Compacter apparatus after being subjected to different storage times. Each sample was compacted at the same temperature using the same compactive effort. The storage times evaluated were 0,3 , and 20 hours. The temperature used in this phase was the target temperature $\left(149^{\circ} \mathrm{C}\right)$ for the specific grade of asphalt cement being used.

Figures 3, 4, and 5 show the average percentage of air voids (VTM), voids in mineral aggregate (VMA), and voids filled with asphalt (VFA) respectively for storage time utilized for each mixture type evaluated.

Figure 3 indicates that the 0 storage time values for the VTM differ from the 3 and 20 hours storage time. Storage a mixture for 3 hours will decrease the VTM about $7.5 \%$ as the average value of the four types of mixtures used compared with the 0 storage time value. 
Increasing the storage time to 20 hours didn't show significant difference from the 3 hours storage time.

Average VMA percentages are given in figure 4 for each storage time. It indicates that storage the mixture to 3 hours will decrease the VMA values by the average of $3.25 \%$ as compared with 0 hours storage time, with remaining the 20 hours storage time have no significant difference from the 3 hours.

Lastly, the average percentages of VFA values for each mixture combination are given in figure 5. Since VFA is calculated using both VTM and VMA, it can be expected that any effect seen in values of VTM and/or VMA will also show differences in VFA. However, 3 hours storage time shows increase in VFA by the $2 \%$ as the average value than the 0 storage time.

In the compaction temperature evaluation, samples of each of the four mixture types were compacted with the same compactive effort but at three different temperatures and 0 hour storage time. The temperature used in this phase was the target temperature for the specific grade of asphalt cement used in the research as well as the target temperature $\pm 14^{\circ} \mathrm{C}$.

Figures 6, 7, and 8 show the average percentages of VTM, VMA, and VFA respectively for compacted temperature utilized for each mixture type evaluated.

Figure 6 shows that decreasing the compacted temperature $14^{0} \mathrm{C}$ from the target compacted temperature will increase the air voids by the average of $7 \%$. Increasing the compacted temperature will decrease the VTM to the average of $5.5 \%$. This may be attributed to the fact with the decreasing of the compacted temperature the viscosity of the asphalt cement will increase and that may need greater effort to sustain the VTM.

Figure 7 shows that decreasing the compacted temperature by $14^{0} \mathrm{C}$ from the target compacted temperature will increase the VMA by the average value of $2 \%$. Increasing the compacted temperature $14^{0} \mathrm{C}$ will decrease the VMA by the average value of $3 \%$.

Figure 8 shows the void filled with asphalt (VFA) with the various compacted temperatures. It indicates that decreasing the compacted temperature by $14^{0} \mathrm{C}$ from the target temperature will decrease the VFA values by the average of $2 \%$. Increasing the compacted temperature will increase the VFA value by the average of $1 \%$.

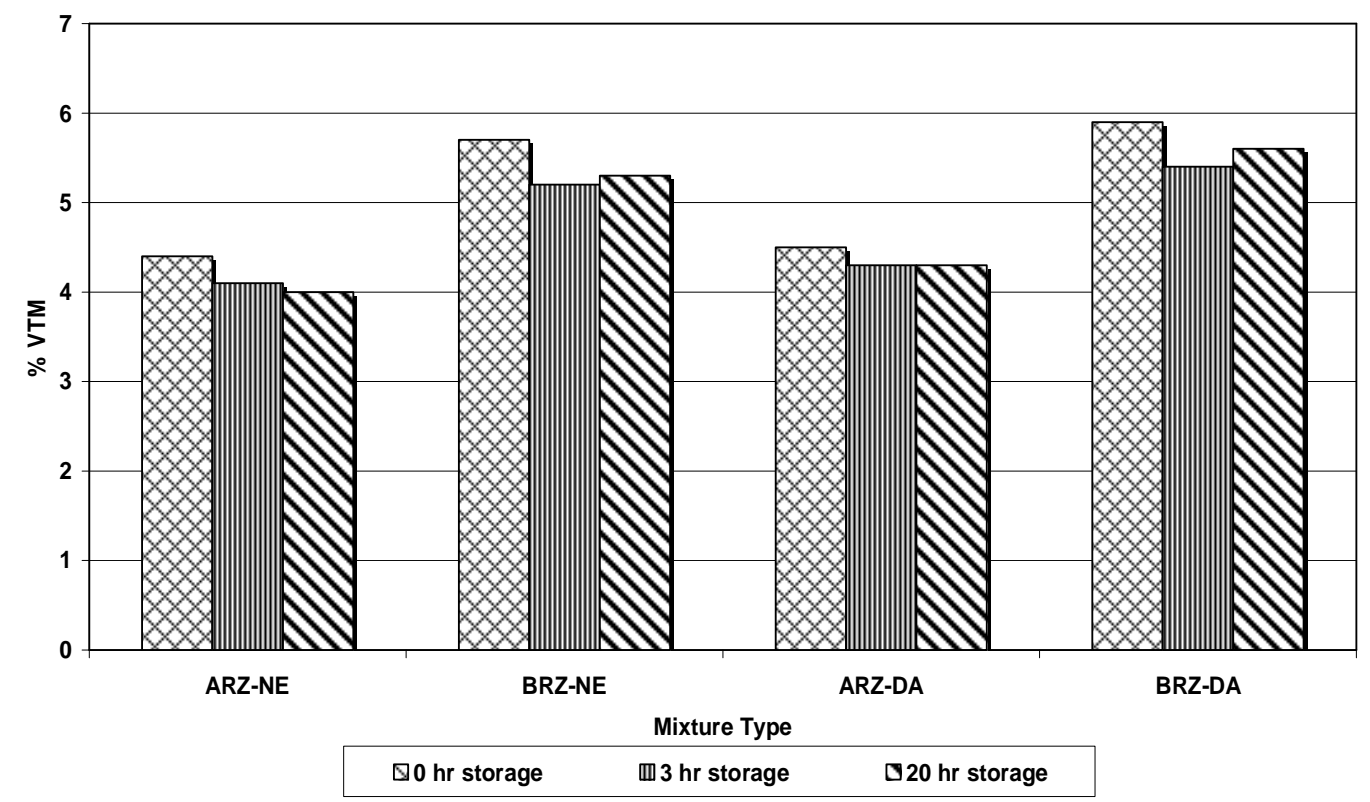

Figure 3: Effect of Storage Time on Voids in Total Mix of Asphalt Concrete Mixture 


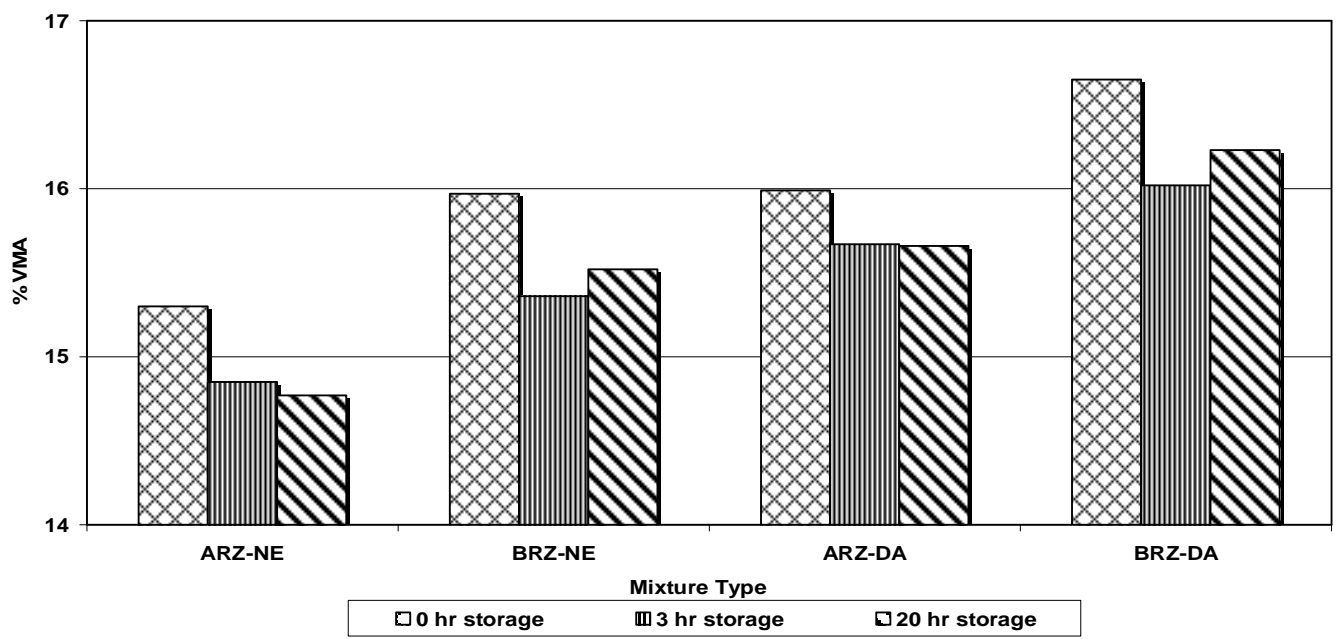

Figure 4: Effect of Storage Time on Voids in Mineral Aggregate of Asphalt Concrete Mixture

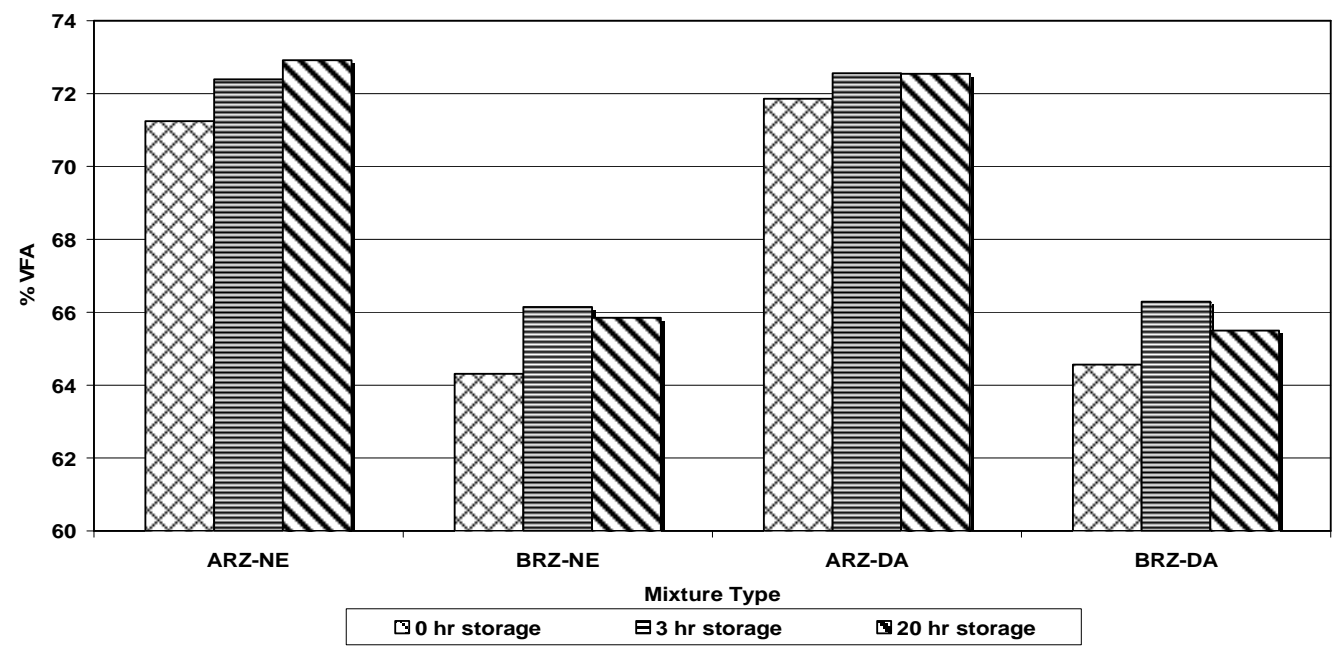

Figure 5: Effect of Storage Time on Voids Filled With Asphalt of Asphalt Concrete Mixture

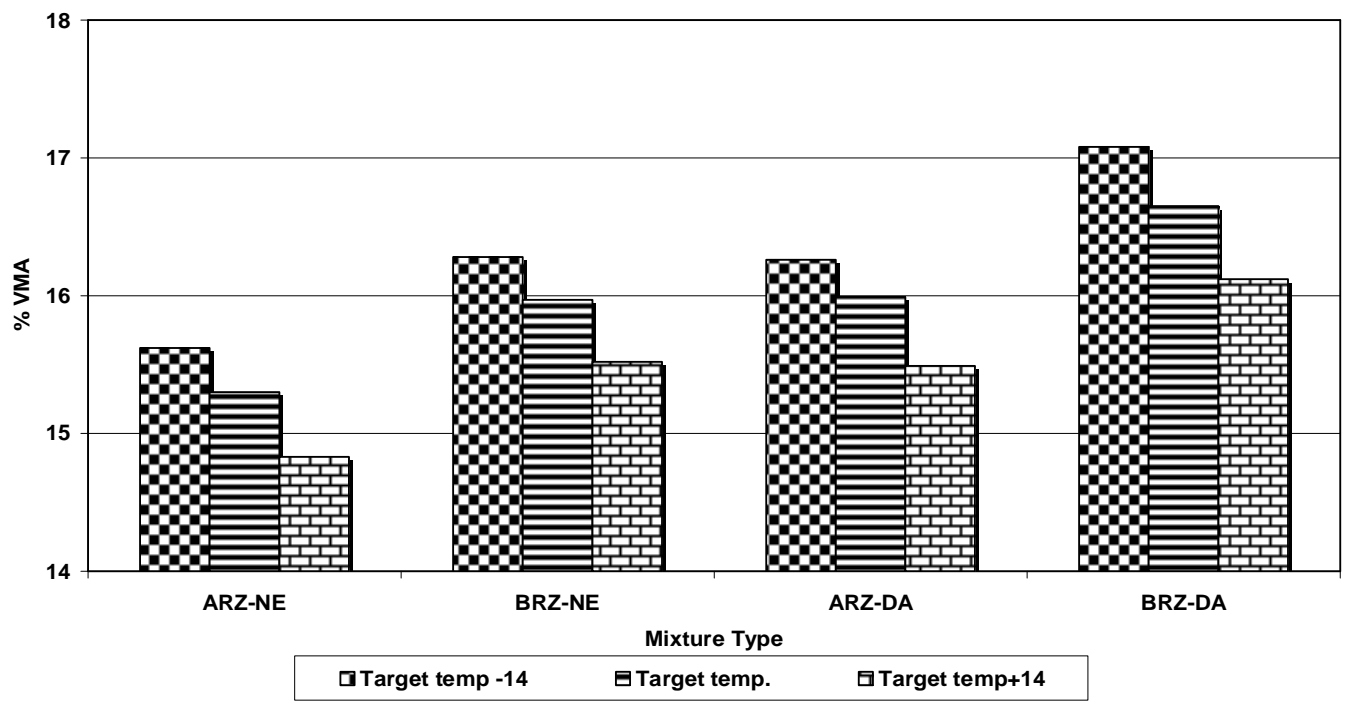

Figure 6: Effect of Compacted Temperature on VTM of Asphalt concrete Mixture 


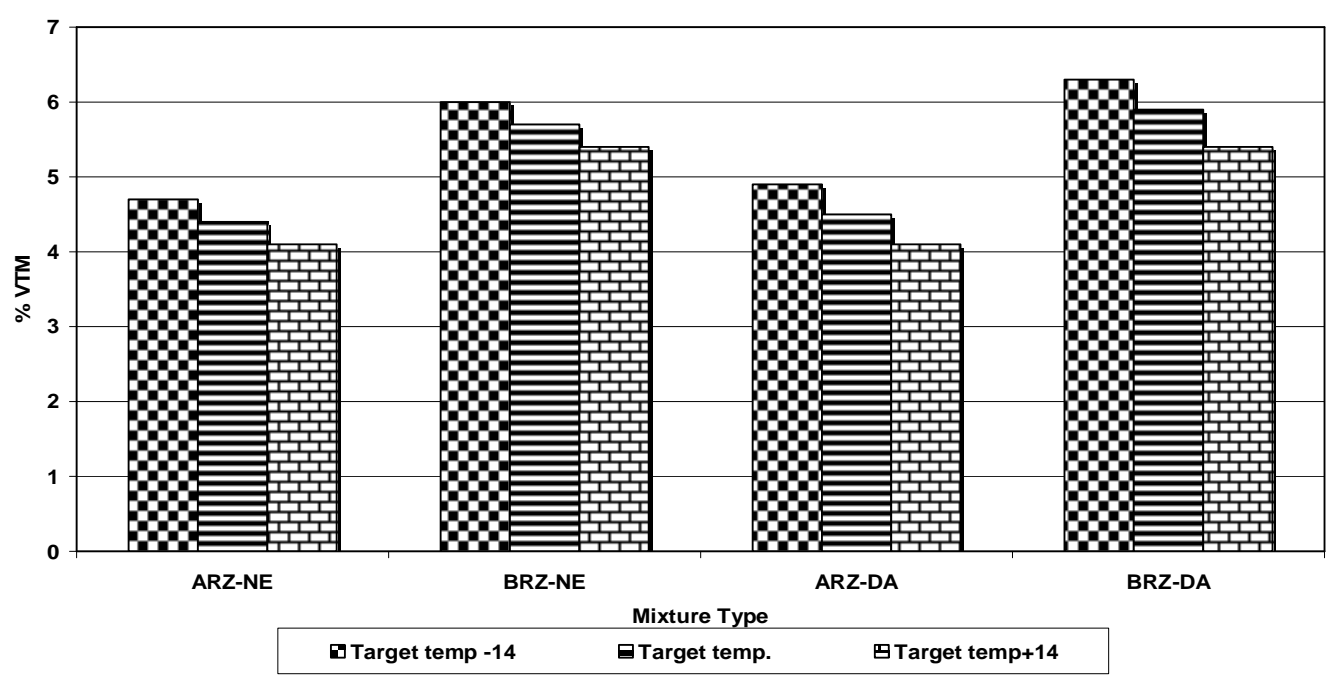

Figure 7: Effect of Compacted Temperature on VMA of Asphalt Concrete Mixture

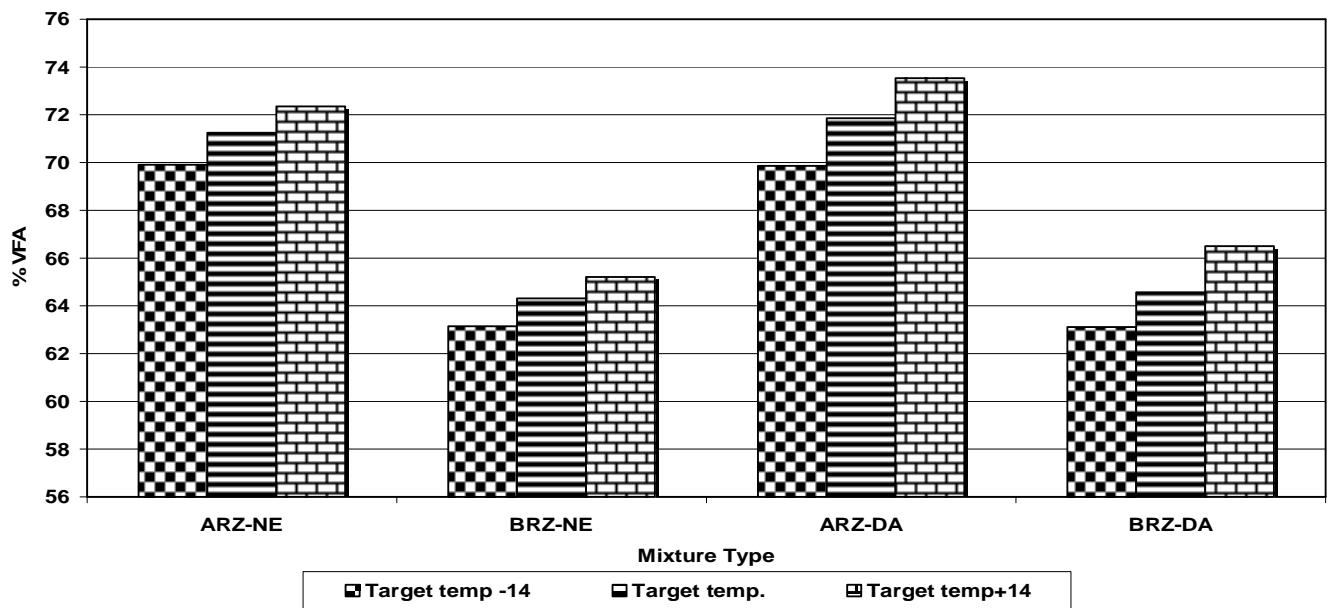

Figure 8: Effect of Compacted Temperature on VFA of Asphalt Concrete Mixture

\section{Conclusion}

Within the limitations of materials and test used in this study the following conclusions are drawn:

1- Storage the mixture to 3 hours have the following effects on volumetric properties

I-Reduce the VTM by $(7.5 \%)$ with respect to the VTM produced from the 0 hour storage time

II- Reduce the VMA by (3.25\%) with respect to the VMA produced from the 0 hour storage time

III-Increase the VFA value by $(2 \%)$ with respect to the VFA produced from the 0 hour storage time

2- Storage the mixture to 20 hours didn't show significant difference from the 3 hours storage time

3- Decreasing the compacted temperature by $14^{0} \mathrm{C}$ from the target temperature shows an increase of the VTM by $7 \%$, increasing the VMA by $2 \%$, and decreasing the VFA by 2 $\%$

4- Increasing the compacted temperature by $14^{0} \mathrm{C}$ from the target temperature shows a reduce of the VTM by $5.5 \%$, reducing the VMA by $3 \%$, and increasing the VFA by $1 \%$ 


\section{References}

1- Asphalt Technology (2000), "Construction, Quality Control and Assurance Training Manual". North Carolina Department of Transportation, Raleigh, North Carolina.

2- Roberts, F.L., and Martin A.E.(1996), "Hot Mix Asphalt Materials, Mixture Design and Construction", NAPA Education Foundation, Lanham, Maryland, Second Edition.

3- Yetkin Y, Mansour S., and Kennedy TH. W. (2000), "Mixing and Compaction Temperatures For Hot Mix Asphalt Concrete", Research Project 0-1250, South Center Superpave Center, Conducted for the Texas Department of Transportation, Research Report Number 1250-5.

4- Bahia, H.U. and Hanson D.I. (2000), "A Project NCHRP 9-10 Superpave Protocols for Modified Asphalt Binders, Draft Topical Report (Task 9)", Prepared for: The National Cooperative Highway Research Program, Transportation Research Board, National Research Council.

5- Parker, Frazier and Shabbir , (1999)," Collection and Analysis of QC/QA Data for Superpave Mixes", National Center for Asphalt Technology.

6- Romel, N.Y. (2004), "Influence of Avoiding the Superpave Restricted Zone on Asphalt Concrete Performance", M.Sc., Thesis, University of Baghdad, Baghdad, pp (44 and 28)

7- Sheelan. A.W. (2002),"Influence of Coarse Aggregate Properties on Performance of Paving Materials", M.Sc., Thesis, University of Baghdad, Baghdad, pp 29.

8- Buchnan, M. SH., and Cooley L. A.(2003), "Investigation of the Tender Zone in the Compaction of coarse-Graded superpave Hot Mix Asphalt (HMA) Mixes", Paper presented at the $82^{\text {nd }}$ Annual Meeting of the Transportation Research Board, Washington.

The work was carried out at the college of Engg. University of Mosul 